\title{
Исследование профиля свободных аминокислот плодов облепихи крушиновидной различных сортов методом тонкослойной хроматографии
}

\author{
(C) 2020 Тринеева О.В., Рудая М.А., Сливкин А.И., Дубовицких М.А. \\ ФГБОУ ВО «Воронежский государственный университет», Воронеж
}

Поступила в редакцию 29.01.2020 г.

DOI: $10.17308 /$ sorpchrom.2020.20/2783

Одной из самых распространенных групп соединений в растениях выступают аминокислоты (АК). Потенциальным источником АК являются плоды облепихи крушиновидной (Ніррорһаё rhamnoides L.) (OK). Полезные свойства данного растения делают его популярным среди населения разных стран, что обуславливает его широкое применение в официальной и народной медицине. Облепиховое масло на основе плодов служит сырьем для производства различных препаратов, применяемых в гинекологии, офтальмологии, дерматологии и гастроэнтерологии. Благодаря богатому комплексу БАВ интерес к этому растению неуклонно возрастает, что способствует его применению не только в области косметической и пищевой промышленности, но также и в фармации для создания новых отечественных лекарственных растительных препаратов.

В данной работе изучен аминокислотный профиль плодов облепихи крушиновидной высушенных различных сортов («Столичная», «Галерит», «Рябиновая», «Ботаническая любительская», «Ботаническая», «Трофимовская», «Студенческая», «Ботаническая ароматная», «Краснокарминовая», «Нивелена»). В результате определения аминокислотного профиля установлено, что вид полученных хроматограмм идентичен для различных сортов плодов ОК высушенных. В использованной элюирующей системе наблюдается удовлетворительное разделение хроматографических зон АК, так как значение селективности сорбции больше единицы. В высушенных плодах ОК различных сортов установлено наличие 3 незаменимых АК (аргинин, валин, фенилаланин) и 3 заменимых АК (пролин, глутаминовая кислота, глицин). Неидентифицированная зона, согласно литературным данным, скорее всего, принадлежит лизину. Полученный ТСХ-профиль аминокислотного состава может быть использован для оценки доброкачественности данного растительного сырья, применяемого для производства лекарственных препаратов на его основе.

Ключевые слова: плоды облепихи крушиновидной различных сортов, тонкослойная хроматография, аминокислоты, хроматографический профиль.

\section{Введение}

Одной из самых распространенных групп соединений в растениях выступают аминокислоты (АК). АК принимают участие в регуляции различных процессов растительного организма: участвуют в синтезе биологически активных соединений (ферментов, витаминов, фитогормонов), обеспечивают защиту от неблагоприятных условий окружающей среды. Воздействуя на человеческий организм, они участвуют в процессах нервной регуляции, оказывают влияние на тонус сосудов, а также тесно взаимосвязаны с процессами восстановления кислорода, что обуславливает их антиоксидантные свойства [1,2].

Изучение фитохимического состава и различных видов фармакологической активности сырья растительного происхождения, экстракционных фитопрепаратов и 
индивидуальных соединений, полученных из растений, приводят к разработке и производству новых эффективных и безопасных лекарственных растительных препаратов (ЛРП) и открывают новые возобновляемые источники для их получения [3]. Около 30\% АК (в пересчете на белок), как свидетельствуют литературные данные, содержится в растениях, не только в связанном, но и свободном состоянии. Данный класс биологически активных веществ (БАВ) очень широко распространен в растениях. Высокая фармакологическая активность АК способствуют эффективному воздействию на организм человека лекарственного растительного сырья (ЛРС) и фитопрепаратов, полученных на его основе. При этом АК в составе общей суммы сопутствующих веществ улучшают фармакокинетические параметры и потенцируют действие основных растительных БАВ [1]. А, следовательно, всестороннее изучение состава АК (качественного и количественного) в ЛРС вызывает научный интерес и имеет практическое значение в плане создания новых отечественных ЛРП для выполнения программы импортозамещения в фармацевтической промышленности.

В последние десятилетия в научной литературе, посвященной вопросам контроля качества лекарственных средств, содержащих АК, авторы отдают предпочтение физико-химическим методам, обладающим такими преимуществами как экспрессность, чувствительность и информативность [4-15]. АК в различных объектах анализа обычно обнаруживают методом бумажной хроматографии. Качественный и количественный состав определяют на аминокислотном анализаторе методом высокоэффективной жидкостной хроматографии [4-15]. В настоящее время тонкослойная хроматография (TCX) применяется в фармацевтическом анализе для установления подлинности и степени чистоты субстанций лекарственных веществ и лекарственных форм. $\mathrm{TCX}$, благодаря присущим ей всем преимуществам хроматографических методов (экспрессность, доступность, достаточная чувствительность, селективность, малая стоимость и простота выполнения анализа), находит все большее применение. Все чаще стали появляться публикации, описывающие возможность количественного анализа данных ТСX при использовании пакета специализированного программного обеспечения [2,5-7]. Широкое применение также находят спектральные методы анализа (УФ- и видимая спектрофотометрия, фотоэлектроколориметрия). Недостатками последних являются: нестабильность окраски продуктов цветных реакций во времени, громоздкость и длительность определений, малая чувствительность и селективность, необходимость предварительного разделения суммы АК, присутствующей во всех растительных объектах $[4,8,9]$.

Потенциальным источником АК являются плоды облепихи крушиновидной (ОК) (Hippophaë rhamnoides L.). Облепиховое масло на основе плодов служит сырьем для производства различных препаратов, применяемых в гинекологии, офтальмологии, дерматологии и гастроэнтерологии. Полезные свойства данного растения делают его популярным среди населения разных стран, что обуславливает его широкое применение в официальной и народной медицине. Благодаря богатому комплексу биологически активных веществ (БАВ) не только в жирном масле, но и в шроте плодов, интерес к этому растению неуклонно возрастает, что способствует его применению не только в области косметической и пищевой промышленности, но также и в фармации для создания новых отечественных лекарственных растительных препаратов. В настоящее время, согласно нормативной документации (НД) ЛРС ОК не стандартизируется по содержанию АК $[2,15]$, составляющих значительную долю гидрофильной фракции [16-20]. Поэтому необходимо учитывать данный показатель при разработке новых проектов и изменении уже существующих фармакопейных статей на ЛРС.

Целью настоящего исследования являлось изучение профиля свободных аминокислот плодов ОК десяти различных сортов методом ТСХ.

Tринеева и др. / Сорбционные и хроматографические процессы. 2020. Т. 20. № 2. С. 277-283 


\section{Эксперимент}

Объектом исследования являлись высушенные плоды ОК различных сортов («Столичная», «Галерит», «Рябиновая», «Ботаническая любительская», «Ботаническая», «Трофимовская», «Студенческая», «Ботаническая ароматная», «Краснокарминовая», «Нивелена»), заготовленные на территории Ботанического сада биологического факультета ФГБОУ ВО «Московский государственный университет» им. М.В. Ломоносова в сентябре 2018 года согласно правилам заготовки ЛРС данной морфологической группы. Сушку плодов производили при температуре $60^{\circ} \mathrm{C}$ до остаточной влажности не более $14 \%$.

Извлечение из плодов ОК для исследования аминокислотного состава проводили по ранее предложенной методике [2]. Для анализа аминокислотного состава плодов ОК различных сортов были использованы хроматографические пластины марки «Sorbfil» ПТСХ-П-А размером 10x15 см (Краснодар, Россия). Для разделения зон АК была использована система н-бутанол - кислота уксусная ледяная - вода (4:1:1), подобранная авторами в ранних работах $[2,15]$. Параллельно на стартовую линию пластинки наносили 2.5 мкл смеси $0.1 \%$ водных растворов стандартных образцов АК (apгинин, глутаминовая кислота, фенилаланин, пролин, лейцин, метионин, валин, глицин) (степень чистоты не менее 99\%; ЗАО «Вектон», СПб, Россия). Идентификацию хроматографических зон АК на пластинах осуществляли путем обработки 1\% раствором нингидрина в этаноле и последующего нагревания в сушильном шкафу при температуре $105^{\circ} \mathrm{C}$ в течение 2-3 минут. Пробы на пластинки наносили с помощью микрошприца объемом 10 мкл (МШ-10, Россия). Для приготовления элюента использовали растворители марки х.ч. (ЗАО «Вектон», СПб, Россия).

\section{Обсуждение результатов}

Для определения оптимального объема пробы на пластинку наносили водное извлечение в диапазоне от 1 до 10 мкл. При этом в интервале 1-4 мкл зоны АК проявлялись слабо, а в диапазоне 7-10 мкл зоны плохо разделялись, сливаясь между собой. Поэтому оптимальным объемом наносимой пробы был выбран объем - 5 мкл. Полученный вид хроматограмм (на примере сорта «Студенческая») представлен на рис.1, а значения величин $\mathrm{R}_{\mathrm{f}}$ хроматографических зон АК приведены в табл. 1.

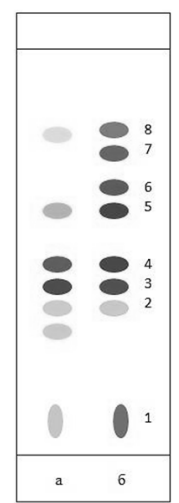

Рис. 1. Вид хроматограммы извлечений из плодов ОК высушенных (a) на примере сорта «Студенческая» после проявления 1\% раствором нингидрина в спирте и смеси стандартных образцов АК (б) (1 - аргинин, 2 - пролин, 3 - глицин, 4 - глутаминовая кислота, 5 - валин, 6 - метионин, 7 - лейцин, 8 - фенилаланин). 
Таблица 1. Результаты изучения ТСХ-профиля свободных АК извлечений из плодов ОК высушенных различных сортов

\begin{tabular}{|c|c|c|c|c|c|c|c|c|c|c|c|}
\hline \multicolumn{10}{|c|}{$\mathrm{R}_{\mathrm{f}}$ 3он на хроматограммах \pm 0.02} & & \multirow{2}{*}{ АК } \\
\hline $1^{*}$ & 2 & 3 & 4 & 5 & 6 & 7 & 8 & 9 & 10 & 11 & \\
\hline 0.075 & 0.067 & 0.075 & 0.080 & 0.081 & 0.081 & 0.075 & 0.075 & 0.074 & 0.065 & 0.086 & Arg \\
\hline 0.185 & 0.240 & 0.277 & 0.260 & 0.243 & 0.155 & 0.175 & 0.160 & 0.165 & 0.203 & - & - \\
\hline 0.285 & 0.280 & 0.319 & 0.330 & 0.290 & 0.254 & 0.225 & 0.208 & 0.215 & 0.268 & 0.264 & Pro \\
\hline 0.327 & 0.327 & 0.369 & 0.375 & 0.340 & 0.295 & 0.260 & 0.250 & 0.247 & 0.317 & 0.303 & Gly \\
\hline 0.353 & 0.360 & 0.403 & 0.425 & 0.390 & 0.352 & 0.316 & 0.308 & 0.297 & 0.357 & 0.370 & Glu \\
\hline 0.470 & 0.470 & 0.504 & 0.516 & 0.487 & 0.459 & 0.416 & 0.408 & 0.420 & 0.479 & 0.503 & Val \\
\hline- & - & - & - & - & - & - & - & - & - & 0.530 & Met \\
\hline 0.590 & 0.630 & 0.660 & 0.675 & 0.690 & 0.610 & 0.590 & 0.583 & 0.595 & 0.640 & 0.613 & Phe \\
\hline- & - & - & - & - & - & - & - & - & - & 0.690 & Leu \\
\hline
\end{tabular}

*1 - Столичная, 2 - Галерит, 3 - Рябиновая, 4 - Ботаническая любительская, 5 -Ботаническая, 6 - Трофимовская, 7 - Студенческая, 8 - Ботаническая ароматная, 9 - Краснокарминовая, 10 - Нивелена, 11 стандартные образцы.

** «-» зона на треке отсутствует

Полученные данные использованы для расчета основных параметров эффективности хроматографического процесса в тонком слое сорбента, таких как величины $\left(\mathrm{R}_{f}\right.$ и $\left.\mathrm{R}_{s}\right)$; коэффициент распределения $(\mathrm{K})$; значение селективности сорбции (L) (табл.2). Расчет проводили по известным формулам [21-23].

Таблица 2. Результаты изучения ТСХ-профиля свободных АК плодов ОК высушенных (на примере сорта «Студенческая»)

\begin{tabular}{|c|c|c|c|c|}
\hline Полученные зоны & $\begin{array}{c}\text { Величина } \\
\mathrm{R}_{\mathrm{f}} \pm .02\end{array}$ & Величина $\mathrm{R}_{\mathrm{s}}$ & $\mathrm{K}$ & $\mathrm{L}=\mathrm{K}_{1} / \mathrm{K}_{2}$ \\
\hline 1 & 0.075 & 0.18 & 12.33 & 2.62 \\
\hline 2 & 0.175 & 0.42 & 4.71 & 1.37 \\
\hline 3 & 0.225 & 0.54 & 3.44 & 1.21 \\
\hline 4 & 0.260 & 0.63 & 2.85 & 1.32 \\
\hline 5 & 0.316 & 0.76 & 2.16 & 1.54 \\
\hline 6 & 0.416 & 1.00 & 1.40 & \multirow{2}{*}{1.94} \\
\hline 7 & 0.583 & 1.40 & 0.72 & \\
\hline
\end{tabular}

На экспериментально определяемые значения $\mathrm{R}_{\mathrm{f}}$ заметно влияют условия хроматографирования. Для надежной идентификации АК необходимо проводить сравнение величин $\mathrm{R}_{\mathrm{f}}$ со стандартными образцами. Более точной оценкой хроматографической подвижности, мало чувствительной к влиянию случайных отклонений в условиях проведения эксперимента, является величина $\mathrm{R}_{s}$, представляющая собой отношение величины $\mathrm{R}_{\mathrm{f}}$ одного вещества к величине $\mathrm{R}_{\mathrm{f}}$ другого вещества, принятого за стандарт $[24,25]$. В табл. 2 представлены значения величин $\mathrm{R}_{\mathrm{s}}$ для AК, выявленных на хроматограммах изучаемых плодов. В качестве стандарта была принята одна из незаменимых АК, имеющая в предложенных условиях хроматографирования оптимальную величину - валин.

В использованной элюирующей системе наблюдается удовлетворительное разделение хроматографических зон АК, так как значение селективности сорбции больше единицы (табл. 2).

В результате определения аминокислотного профиля установлено, что вид полученных хроматограмм идентичен для различных сортов плодов ОК высушенных. 
На хроматограммах извлечений обнаружено 7 зон АК, 6 из которых идентифицировано с помощью стандартных образцов (аргинин, пролин, глицин, глутаминовая кислота, валин, фенилаланин).

Следует отметить, что провести сравнение полученных в статье результатов с аналогичными исследованиями других авторов России и Зарубежья, несмотря на имеющийся в литературе обширный цикл подобных работ ученых Сибири (Золотарева А.М., Кошелев Ю.А. и др.) [17,18,26], Беларуси [27], Польши [28], КНР [16], Индии, Пакистана и др. [29], не представляется возможным, так как пробоподготовка ЛРС для выделения комплекса АК, а также условия хроматографирования неодинаковы, а, следовательно, сравнение полученных в разных условиях эксперимента результатов являются некорректными.

\section{Заключение}

Таким образом, установлено, что аминокислотный набор высушенных плодов ОК десяти различных сортов идентичен. Полученные данные свидетельствуют о присутствии на хроматограммах извлечений 7 зон свободных АК, среди которых 6 зон идентифицировано с помощью стандартных образцов АК. В высушенных плодах ОК различных сортов установлено наличие 3 незаменимых АК (аргинин, валин, фенилаланин) и 3 заменимых АК (пролин, глутаминовая кислота, глицин). Неидентифицированная зона, согласно литературным данным [3-7], скорее всего, принадлежит лизину. Полученный ТСХ-профиль аминокислотного состава может быть использован для оценки подлинности данного растительного сырья, применяемого для производства лекарственных препаратов на его основе.

\section{Список литературы}

1. Арутунянц А.А., Саламова Н.А., Лохов Р.Е. // Башкирский хим. журнал. 2012. № 1. Т. 19. C. $169-171$.

2. Тринеева О.В. Комплексное исследование содержания и специфического профиля биологически активных веществ плодов облепихи крушиновидной: монография. Воронеж: Издательский дом ВГУ. 2016. 224 с.

3. Кхалед Абу Захер, Журавлев Н.С. // Электронный журнал «Провизор». 2001. № 21. http://www.provisor.com.ua/

4. Олешко Г.И., Ярыгина Т.И., Зорина Е.В., Решетникова М.Д. // Фармачия. 2011. № 3. С. 14-17.

5. Малахова И.И., Красиков В.Д., Тяглов Б.В., Дегтерев Е.В. Патент РФ №2095808.

6. Тяглов Б.В., Дегтерев Е.В., Малахова И.И. и др. Патент РФ №2078342.

7. Голованов В.Г., Петровский А.А., Кельник Н.В. и др. Патент SU №1642373.

8. Ярыгина Т.И., Захаров А.В., Дубовик В.А. Патент РФ №2167410.

9. Khokhani K., Ram V., Bhatt J., Khatri T., Joshi H. // International Journal of ChemTech Research. 2012. Vol. 4. No 1. pp. 389-393.
10.Elbashir A.A., Suliman F.E.O., AboulEnein H.Y. // GU J. Sci. 2011. Vol. 24(4). pp. 679-697.

11.Rubio-Barroso S., Santos-Delgado M.J., Martin-Olivar C., Polo-Diez L.M. // J. Dairy Sci. Vol. 89. pp. 82-89.

12.Calabrese M., Stancher B., Riccobon P. // J. Sci. Food Agric. 1995. Vol. 69. pp. 361-366.

13.Herbert P., Barros P., Ratola N., Alves A. // J. Food Sci. 2000. Vol. 65. pp. 1130-1133.

14.Hernandez-Orte P., Ibarz M.J., Cacho J., Ferreira V. // Chromatographia. 2003. Vol. 58. pp. 29-35.

15.Тринеева О.В., Синкевич А.В., Сливкин А.И., Сафонова Е.Ф. // Сорбиионные и хроматографические проиессы. 2015. Т. 14. № 3. С. 530-536.

16. Cheng Tigong, Ni Ming Kang, Li Rong, Ji Fen // Химия природных соединений. 1991. № 1. C. 135-137.

17.Золотарева А.М., Чиркина Т.Ф., Гончикова С.Д., Карпенко Л.Д. // Изв. вузов. Пищевая технология. 1994. № 1-2. С. 24-26.

18.Золотарева А.М. Автореф. дисс. докт. техн. н. Улан-Удэ, 2004. 32 с. 
19.Солоненко Л.П., Лоскутова Г.А., Дружкова Т.А., Шёрсткин А.Ф. // Новое в биологии, химии и фармакологии облепихи. 1991. №6. С. 79-85.

20.Карпова Е.А. Автореф. дисс. канд. техн. н. Новосибирск. 1999. 25 с.

21. Рудаков О.Б., Востров И.А., Федоров С.В. и др. Спутник хроматографиста. Методы жидкостной хроматографии. Воронеж. «Водолей». 2004. 528 c.

22. Кирхнер Ю. Тонкослойная хроматография. М. «Мир». 1981. С. 402-407.

23. Гейсс Ф. Основы тонкослойной хроматографии. М. «Мир». 1999. 405 с.

24.Государственная фармакопея Российской Федерации XIV изд. Режим доступа: http://femb.ru/femb/pharmacopea.php (дата обращения 15.08.2019).
25.Государственная Фармакопея Российской Федерации XIII изд. Режим доступа: http://www.rosminzdrav.ru/ministry/61/11/mate rialy-po-deyatelnosti-deparatamenta/stranitsa-

856/spisok-obschih-farmakopeynyh-statey (дата обращения 15.08.2019).

26.Кошелев Ю.А., Агеева Л.Д. Облепиха: монография. Бийск. НИЦ БПГУ им. В.М. Шукшина. 2004. 320 с.

27.Зенькова М.Л., Тимофеева В.Н., Акулич А.В. // Хранение и переработка сельхозсырья. 2007. №8. C. 24-26.

28.Adrianna Rafalska, Katarzyna Abramowicz, Magdalena Krauze // World Scientific News. 2017. 72. C. 123-140.

29. Sabir S.M., Magsood H., Hayat I.et al. // J Med Food. 2005. Vol. 8(4). pp. 518-522.

\title{
Study of the profile of free amino acids of sea buckthorn fruits of various varieties by thin layer chromatography
}

\author{
(C) 2020 Trineeva O.V., Rudaya M.A., Slivkin A.I., Dubovitsky M.A. \\ Voronezh State University, Voronezh
}

\begin{abstract}
Amino acids (AA) is one of the most common groups of compounds in plants. A potential source of AAs are the fruit of sea buckthorn (Hippophaë rhamnoides L.) (SB). This plant is popular among people of different countries due to its useful properties and is widely used in official and traditional medicine. Fruitbased sea buckthorn oil serves as a raw material for the production of various drugs used in gynaecology, ophthalmology, dermatology, and gastroenterology. Thanks to the rich complex of biologically active substances, the interest in this plant is steadily increasing, which contributes to its use not only in the field of cosmetic and food industries, but also in pharmacy where it can be applied to create new home-produced herbal medicines.

This article investigates into the amino acid profile of dried buckthorn fruit of several varieties (Stolichnaya, Galerit, Ryabinovaya, Amateur Botanical, Botanical, Trofimovskaya, Student, Botanical Aromatic, Krasnokarminovaya, Nivelena). The study of the amino acid profile revealed that the obtained chromatograms are identical for different varieties of dried SB fruit. The applied eluent system yielded satisfactory separation of chromotographic zones of AAs, as the selectivity coefficient is above 1. It was found that dried SB fruits of different varieties have 3 irreplaceable AAs (arginine, valine, phenylalanine) and 3 replaceable AAs (proline, glutamic acid, glycine). According to published data, the unidentified zone most likely belongs to lysine. The obtained TLC-profile of the amino acid composition can be used to assess positive qualities of this plant material used for the production of drugs.
\end{abstract}

Keywords: fruit of sea-buckthorn of several varieties, thin-layer chromatography, amino acids, chromatographic profile

\section{References}

1. Arutunyants A.A., Salamova N.A., Lokhov R.E., Bashkirskiikhim. Zhurnal, 2012, No 1, Vol. 19, pp. 169-171.

2. Trineeva O.V. Kompleksnoeissledovaniesoderzhaniyaispetsificheskogoprofilyabiologicheskiaktivnykhveshchestvplodovoblepi khikrushinovidnoi: monografiya, Voronezh, Izdatel'skiidom VGU, 2016, 224 p.

3. Kkhaled Abu Zakher, Zhuravlev N.S., Elektronnyizhurnal «Provizor», 2001, No 21, http://www.provisor.com.ua/ 
4. Oleshko G.I., Yarygina T.I., Zorina E.V., Reshetnikova M.D., Farmatsiya, 2011, No 3, pp. 14-17.

5. Malakhova I.I., Krasikov V.D., Tyaglov B.V., Degterev E.V. Patent RF №2095808.

6. Tyaglov B.V., Degterev E.V., Malakhova I.I. idr. Patent RF №2078342.

7. Golovanov V.G., Petrovskii A.A., Kel'nik N.V. idr. Patent SU №1642373.

8. Yarygina T.I., Zakharov A.V., Dubovik V.A. Patent RF №2167410.

9. Khokhani K., Ram V., Bhatt J., Khatri T., Joshi H., International Journal of ChemTech Research, 2012,Vol. 4, No 1, pp. 389-393.

10. Elbashir A.A., Suliman F.E.O., AboulEnein H.Y., GU J. Sci, 2011, Vol. 24(4), pp. 679697.

11. Rubio-Barroso S., Santos-Delgado M.J., Martin-Olivar C., Polo-Diez L.M., J. Dairy Sci., Vol. 89, pp. 82-89.

12. Calabrese M., Stancher B., Riccobon P., $J$. Sci. Food Agric., 1995, Vol. 69, pp. 361-366.

13. Herbert P., Barros P., Ratola N., Alves A., J. Food Sci., 2000, Vol. 65, pp. 1130-1133.

14. Hernandez-Orte P., Ibarz M.J., Cacho J., Ferreira V., Chromatographia, 2003, Vol. 58, pp. 29-35.

15. Trineeva O.V., Sinkevich A.V., Slivkin A.I., Safonova E.F. Sorbtsionnye $i$ khromatograficheskie protsessy, 2015, Vol. 14, No 3, pp. 530-536.

16. Cheng Tigong, Ni Ming Kang, Li Rong, Ji Fen, Khimiya prirodnykh soedinenii, 1991, No 1, pp. 135-137.

17. Zolotareva A.M., Chirkina T.F., Gonchikova S.D., Karpenko L.D., Izv. vuzov. Pishchevaya tekhnologiya, 1994, No 1-2, pp. 2426.

Тринеева Ольга Валерьевна - д.фарм.н., доцент кафедры фармацевтической химии и фармацевтической технологии фармацевтического факультета ВГУ, Воронеж

Рудая Маргарита Александровна - аспирант 3ого года обучения фармацевтического факультета ВГУ, Воронеж

Сливкин Алексей Иванович - д.фарм.н., профессор, зав. кафедрой фармацевтической химии и фармацевтической технологии, декан фармацевтического факультета ВГУ, Воронеж

Дубовицких Марина Александровна - студентка 3-его курса фармацевтического факультета ВГУ, Воронеж
18. Zolotareva A.M. Avtoref. diss. dokt. tekhn. n. Ulan-Ude, 2004, 32 p.

19. Solonenko L.P., Loskutova G.A., Druzhkova T.A., Sherstkin A.F., Novoe v biologii, khimiiifarmakologiioblepikhi, Novosibirsk, 1991, No 6, pp. 79-85.

20. Karpova E.A. Avtoref. diss. kand. tekhn. n. Novosibirsk, 1999. 25 p.

21. Rudakov O.B., Vostrov I.A., Fedorov S.V. et al. Sputnik khromatografista. Metody zhidkostnoi khromatografii. Voronezh, «Vodolei», 2004, $528 \mathrm{p}$.

22. Kirkhner Yu. Tonkosloinaya khromatografiya. M., «Mir», 1981, pp. 402-407.

23. Geiss F. Osnovy tonkosloinoi khromatografii. M., «Mir», 1999, 405 p.

24. Gosudarstvennaya farmakopeya Rossiiskoi Federatsii XIV izd. Rezhim dostupa: http://femb.ru/femb/pharmacopea.php (data obrashcheniya 15.08.2019).

25. Gosudarstvennaya Farmakopeya Rossiiskoi Federatsii XIII izd. Rezhim dostupa: http://www.rosminzdrav.ru/ministry/61/11/materialy-po-deyatelnosti-deparatamenta/stranitsa856/spisok-obschih-farmakopeynyh-statey (data obrashcheniya 15.08.2019).

26. Koshelev Yu.A., Ageeva L.D. Oblepikha: monografiya. Biisk: NITs BPGU im. V.M. Shukshina, 2004, $320 \mathrm{p}$.

27. Zen'kova M.L., Timofeeva V.N., Akulich A.V., Khranenie $i$ pererabotka sel'khozsyr'ya, 2007, No 8, pp. 24-26.

28. Adrianna Rafalska, Katarzyna Abramowicz, Magdalena Krauze, World Scientific News, 2017, 72, pp. 123-140.

29. Sabir S.M., Magsood H., Hayat I. et al., $J$ Med Food., 2005, No 8(4), pp. 518-522.

Trineeva Olga V. - doctor of pharmaceutical sciences, associate professor of pharmaceutical chemistry and pharmaceutical technology of pharmaceutical faculty of Voronezh State University, Voronezh, e-mail: trineevaov@mail.ru

Rudaya Margarita A. - a graduate student of the $3^{\text {rd }}$ year students of pharmaceutical faculty of Voronezh State University, Voronezh

Slivkin Alexey I. - doctor of pharmaceutical sciences, professor, manager. chair of pharmaceutical chemistry and pharmaceutical technology, dean of pharmaceutical faculty of Voronezh State University, Voronezh, e-mail: slivkin@pharmvsu.ru

Dubovitskich Marina A. $-3^{\text {rd }}$ year student ofpharmaceutical faculty of Voronezh State University, Voronezh 